\title{
Correspondence
}

\section{Laryngeal mask for failed intubation in emergency Caesarean section}

To the Editor:

We wish to present a case of failed intubation in a short, obese patient for emergency c-section for fetal distress which was successfully managed by the early use of the Brain laryngeal mask (BLM).

\section{Case report}

A 37 -yr-old woman, weighing $87 \mathrm{~kg}$ for a height of 155 $\mathrm{cm}$, in her fifth pregnancy was presented for emergency Caesarean section for fetal distress.

After the patient was placed in the left lateral decubitus on the operating table she was attached to ECG monitor, automatic BP monitor and pulse oximeter.

After preoxygenation, the patient received alcuronium $0.03 \mathrm{mg} \cdot \mathrm{kg}^{-1}$ followed two minutes later by thiopentone sodium $4 \mathrm{mg} \cdot \mathrm{kg}^{-1}$ and succinylcholine $1.2 \mathrm{mg} \cdot \mathrm{kg}^{-1}$, with cricoid pressure applied by a qualified assistant. Under direct laryngoscopy the visualization of the larynx was impossible and two attempts to intubate the trachea, one performed by a senior anaesthetist, failed. The lungs continued to be ventilated by mask with cricoid pressure maintained until a Brain laryngeal mask \#4 was inserted easily without the use of an introducer or a laryngoscope. Anaesthesia continued uneventfully, with the patient making a full recovery.

The use of the BLM in failed intubation in the obstetric patient proved to be life-saving in previous reported cases $^{1,2}$ and was extremely useful in our case. We feel that the decision to use a BLM during a failed intubation situation should be made very early. Perhaps the priorities of the various failed intubation drills should be changed and include the early introduction of BLM.

\section{Virgil Priscu MD \\ Lilia Priscu MD \\ David Soroker MD \\ Department of Anesthesia \\ Kaplan Hospital, Rehovot}

Affiliated to the Hebrew University and

Hadassah-Jerusalem, Israel.

\section{REFERENCES}

1 McClune S, Reagan M, Moore J. Laryngeal mask airway for Caesarean section. Anaesthesia 1990; 45: 227-8.

2 Chadwick IS, Vohra A. Anaesthesia for emergency caesarean section using the Brain laryngeal airway. Anaesthesia 1989; 44: 261-2.

3 Calder I, Ordman AJ, Jakowski A, Crockard HA. The Brain laryngeal mask airway. An alternative to emergency tracheal intubation. Anaesthesia 1990; 45: 137-9.

4 Thompson KD, Ordman AJ, Parkhouse N, Morgan BDG. Use of the Brain laryngeal mask airway in anticipation of difficult intubation. Br J Plast Surg 1989; 42: 478-80.

\section{Anaesthesia for outpatient TURP}

To the Editor:

Transurethral prostatectomy (TURP) is a relatively recent addition to the range of surgery carried out on a daycare basis. "There is a lack of information in the literature regarding anaesthesia for this procedure in the outpatient setting. When TURP is performed as an inpatient procedure it is typically carried out under sub-arachnoid block but there has been concern regarding the suitability of this kind of anaesthesia for outpatient surgery because of the reported high incidence of postdural puncture headache (PDPH). ${ }^{2}$

It was therefore decided to conduct post-discharge interviews with patients who had undergone outpatient TURPs to establish the incidence of side effects following $\mathrm{SAB}$ or general anaesthesia. One hundred and two consecutive patients were contacted by telephone four days following their surgery by an investigator blinded to the anaesthetic administered and answered a questionnaire designed to identify the occurrence of all commonly reported side effects of general and spinal anaesthesia. The hospital chart was then reviewed and the anaesthetic and recovery room course recorded.

Fifty-five patients received $\mathrm{SAB}$ via a 25 or 27 gauge Quinke point needle and 47 received general anaesthesia consisting principally of thiopentone, nitrous oxide, narcotic and a volatile agent. Twenty-nine patients reported post-anaesthetic headaches, 16 after general anaesthesia and 13 after $\mathrm{SAB}$. Three patients in each group reported severe headaches, those in the $S A B$ group meeting the criteria for PDPH. None of the latter three 